\title{
Cyclone Activities in Heavy Rainfall Episodes in Japan during Spring Season
}

\author{
Masamitsu Hayasaki and Ryuichi Kawamura \\ Section of Earth and Environmental Systems, Graduate School of Science and Engineering for Research, \\ University of Toyama, Toyama, Japan
}

\begin{abstract}
Characteristics of springtime cyclones with heavy rainfall in Japan are examined. Heavy rain episodes are obtained from the upper five percent of an area-averaged daily rainfall in the mainland Japan for the period 1982-2009. For heavy rain episodes, the cyclogenesis area shifts westward. The primary path of cyclones, locates along the south coast of Japan, displaces northward from the climatological path and that of the moderate rain episodes. Maximum developments of cyclones are frequently observed over the East China Sea and western Japan near the oceanic frontal zone. A composite analysis of heavy rain episodes exhibits that a lower tropospheric ridge covers Japan two days before a heavy rain date (Day -2$)$. The ridge, which locates to the east of the trough, amplifies and extends meridionally with eastward progress until Day 0 . As the eastward migration of the trough and ridge, poleward moisture flux is enhanced between the trough and ridge systems. In moderate rain episodes, amplification of trough and ridge systems and associated poleward moisture flux are rather weak for the period around Day 0. Enhanced poleward moisture flux due to the amplification of both trough and ridge may cause early development and northward shift of cyclones.
\end{abstract}

\section{Introduction}

Rainfall amount and its spatial distribution in Japan show notable seasonal variations. During the cold season, continental cold air outbreaks cause shallow convective cloud streets over the Sea of Japan. These clouds bring heavy snowfall along the coastal area. The northwesterly monsoon surges also affect the behavior of explosively developing cyclones around Japan. Maximum developments of explosive cyclones tend to concentrate in the vicinity of the Kuroshio Current and the Kuroshio Extension for a strong winter monsoon period (Yoshiike and Kawamura 2009). In a warm season, a southwesterly flow prevails over Southeast and East Asia. The intensified southwesterly flow forms a stationary front ('Baiu' front) and causes heavy rainfall along the front. In spring, however, widespread rainfall in Japan is mainly caused by traveling extratropical cyclones.

On the basis of a cyclone tracking analysis using weather charts, cyclone frequencies around Japan are largest in spring (Whittaker and Horn 1984; Asai et al. 1988; Chen et al. 1992). General characteristics of synoptic weather conditions for heavy rainfall (snowfall) periods were documented well in previous studies as for summer (e.g., Ninomiya 1984; Takahashi 1993) and winter (e.g., Yoshiike and Kawamura 2009).

Comprehensive descriptions of springtime cyclones with heavy rainfall have not been fully documented. Spring cyclones are most frequent and cause disastrous winds and widespread heavy rain episodes in Japan (Uemura 1981; Nishii et al. 2009). The main purpose of this study is to examine the characteristics of cyclones with heavy rain in Japan during the spring season.

Corresponding author and present affiliation: Masamitsu Hayasaki, Department of Earth and Planetary Sciences, Faculty of Sciences, Kyushu University, 6-10-1 Hakozaki, Higashi-ku, Fukuoka 812-8581, Japan. E-mail hayasaki.masamitsu.695@m.kyushu-u.ac.jp. C2012, the Meteorological Society of Japan.

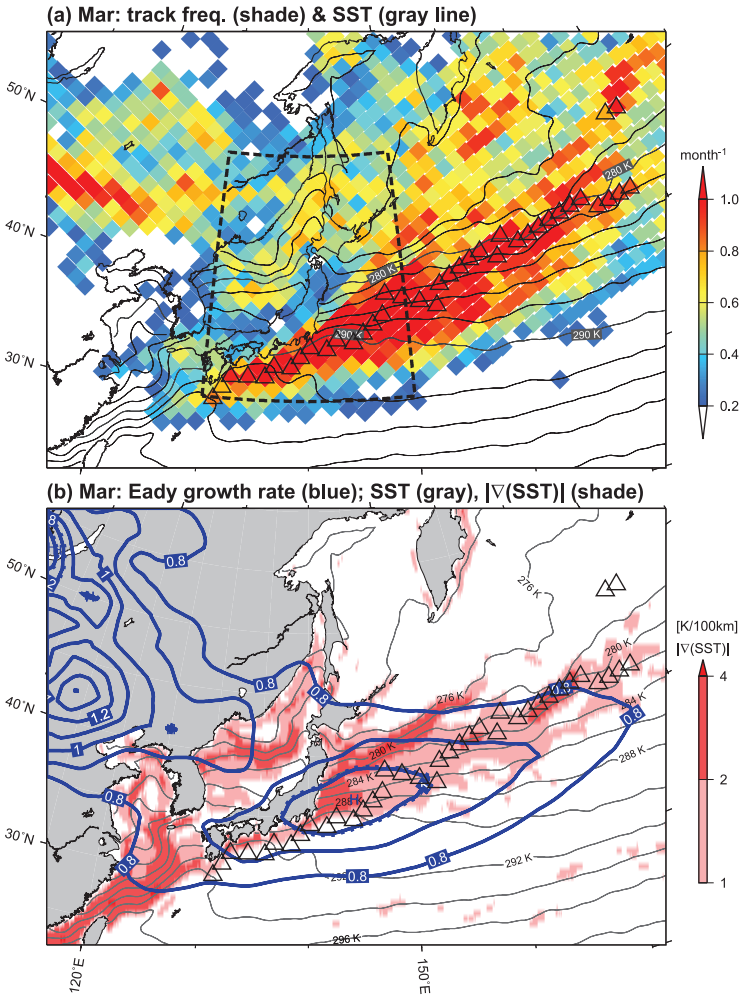

Fig. 1. Monthly climatology (March 1982-2009) of (a) cyclone track frequencies (count/month) and (b) horizontal sea surface temperature $(\mathrm{SST})$ gradient (shade, $\left.|\nabla \mathrm{SST}| \geq 1.0 \mathrm{~K}(100 \mathrm{~km})^{-1}\right)$ and the maximum Eady growth rate (blue line, $\sigma \equiv 0.31 f$ $|\partial \boldsymbol{V} / \partial z| N^{-1} ; \sigma \geq 0.8$ day $^{-1}$. See Hoskins and Valdes (1990)). Area surrounded by dashed line $\left(30^{\circ} \mathrm{N}-50^{\circ} \mathrm{N}, 130^{\circ} \mathrm{E}-150^{\circ} \mathrm{E}\right)$ is the study area. Triangles represent primary path of cyclones $\left(130^{\circ} \mathrm{E}-\right.$ $\left.180^{\circ}\right)$. Thin solid lines show climatological SST (2 K interval).

\section{Data}

The gridded daily rainfall data in Japan (APHRO JP) were obtained from the Asian Precipitation Highly-Resolved Observational Data Integration Towards Evaluation (APHRODITE) of Water Resources project (Yatagai et al. 2009). The APHRO_JP data have $0.05^{\circ} \times 0.05^{\circ}$ spatial resolution in Japan $\left(24^{\circ} \mathrm{N}-46^{\circ} \mathrm{N}\right.$, $\left.123^{\circ} \mathrm{E}-146^{\circ} \mathrm{E}\right)$. Details of these data are fully documented in Kamiguchi et al. (2010). Data from the Japanese 25-year Reanalysis/Japan Meteorological Agency (JMA) Climate Data Assimilation System (JRA25/JCDAS) (Onogi et al. 2007) were used to analyze atmospheric circulation fields. The spatial and temporal intervals were $1.25^{\circ}$ and 6 hours, respectively. Long-term seasurface temperature (SST) data were obtained from the AVHRR products of the optimally interpolated (OI) SST (Reynolds et al. 2007). The analysis period of this study ranged from 1982 through 2009.

Procedures for detecting and tracking cyclones were based 
(a) Mar: heavy rain days (43-case)
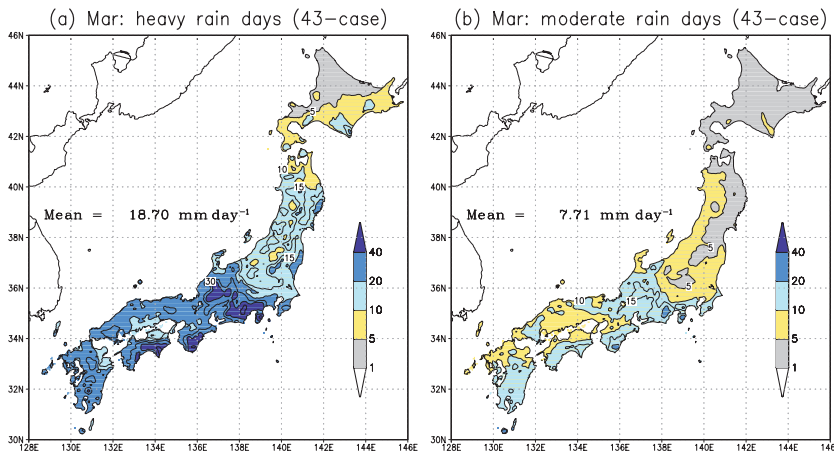

Fig. 2. Composites of rain rate $\left(\mathrm{mm} \mathrm{day}^{-1}\right)$ for (a) heavy and (b) moderate rain episodes in March.

on Serreze et al. (1993), with slight modifications. That is, a lat/long gridded SLP was converted into the Equal Area Scalable Earth (EASE) grid (see more details in http://nsidc.org/data/ease/ ease_grid.html). The Northern Hemisphere EASE grid has 145 $\times 1 \overline{45}$ grids with $125 \mathrm{~km}$ intervals at the North Pole. A cyclone center was identified by the SLP minimum. A threshold value of SLP differences from surrounding grids were $0.5 \mathrm{hPa}$ in this study. For tracking, we set a search area to find a candidate cyclone at the next time step. The search area was based on a \pm 4 grid ranging from the center of the previous cyclone. If no candidate cyclones appeared within the search area, the cyclone was considered to have dissipated at that time. To eliminate locally-induced cyclones (i.e., thermal lows in the land area), we disregarded short-lived cyclones (total lifetime $<24 \mathrm{hr}$ ) in this study.

To validate the cyclones identified by this method, we manually checked them using surface weather charts provided by JMA. Most of the identified cyclones and their tracks showed good agreement with those determined manually. Smaller-scale cyclones (i.e., secondary cyclones on a front) analyzed using the JMA weather chart frequently missed detection or tracking in our tracking method. The general features of cyclone activities (geographical locations of major paths, cyclone frequency, and seasonal variations; see supplements) showed good agreement with those described in previous studies (e.g., Asai et al. 1988; Chen et al. 1991). Although the frequency of explosive cyclones was slightly underestimated $(-15 \%)$ compared with the results obtained by Yoshida and Asuma (2004), the major path of explosive cyclones and its seasonal variations were quite similar to those found in their study (not shown). As noted by Chen et al. (1991) and Asai et al. (1988), there are three cyclone tracks around Japan: (1) the Pacific coastal track, (2) the Japan Sea track $\left(\sim 40^{\circ} \mathrm{N}\right)$, and (3) the Asian continent track $\left(\sim 50^{\circ} \mathrm{N}\right)$. The latter two tracks are frequent in autumn and spring. The primary path of cyclones (grid with the largest frequencies along row direction of the EASE grid; see Supplement 1) is the Pacific coastal track, which starts from the southwestern tip of the Japanese Islands and extends northeastward to the western North Pacific in the vicinity of the Kuroshio Current and the Kuroshio Extension. In spring, while the growth rate of baroclinic eddies is smaller than that in winter, a cyclone frequency is greatest in March (Fig. 1). As the season progresses, the Pacific coastal track shifts northward off the east coast of Japan.

\section{Results}

In this section, we focus on springtime cyclone activities associated with nationwide rainfall episodes in Japan. Heavy rain days in March are obtained from the upper five percent (43 days) of area-averaged daily rainfall ([P]) in mainland Japan $\left(30^{\circ} \mathrm{N}-46^{\circ} \mathrm{N}\right.$, $\left.128^{\circ} \mathrm{E}-146^{\circ} \mathrm{E}\right)$. If other heavy rainfall days are found within 3 days of the targeted date, we choose the date with the largest [P] as the key date (Day 0). We also extract "moderate rain" episodes
Table 1. Cyclone statistics (number of lows, minimum SLP, and maximum developing rate (DR)) for heavy and moderate rain episodes in March. Averages (ave) and standard deviations (std) of minimum SLP (unit: $\mathrm{hPa}$ ) and maximum DR (unit: bergeron; see Sanders and Gyakum 1980) are obtained from selected samples. Statistics of all cyclones (1982-2009) are shown at the bottom. The numbers in parentheses to the right of cyclone counts indicate the number of explosive cyclones (DR $\geq 1.0$ bergeron).

\begin{tabular}{|c|c|c|c|c|c|c|}
\hline & \multicolumn{2}{|c|}{ \# cyclones } & \multicolumn{2}{|c|}{$\min$ SLP } & \multicolumn{2}{|c|}{$\max . \mathrm{DR}$} \\
\hline & total & (bomb) & ave & std & ave & std \\
\hline heavy & 52 & $(27)$ & 997.3 & 9.0 & 1.11 & 0.493 \\
\hline moderate & 44 & $(20)$ & 999.1 & 8.6 & 1.02 & 0.497 \\
\hline all & 404 & (176) & 1000.3 & 8.3 & 0.95 & 0.600 \\
\hline
\end{tabular}

(a) Heavy rain; \# tracks (color) \& max develop (circle)

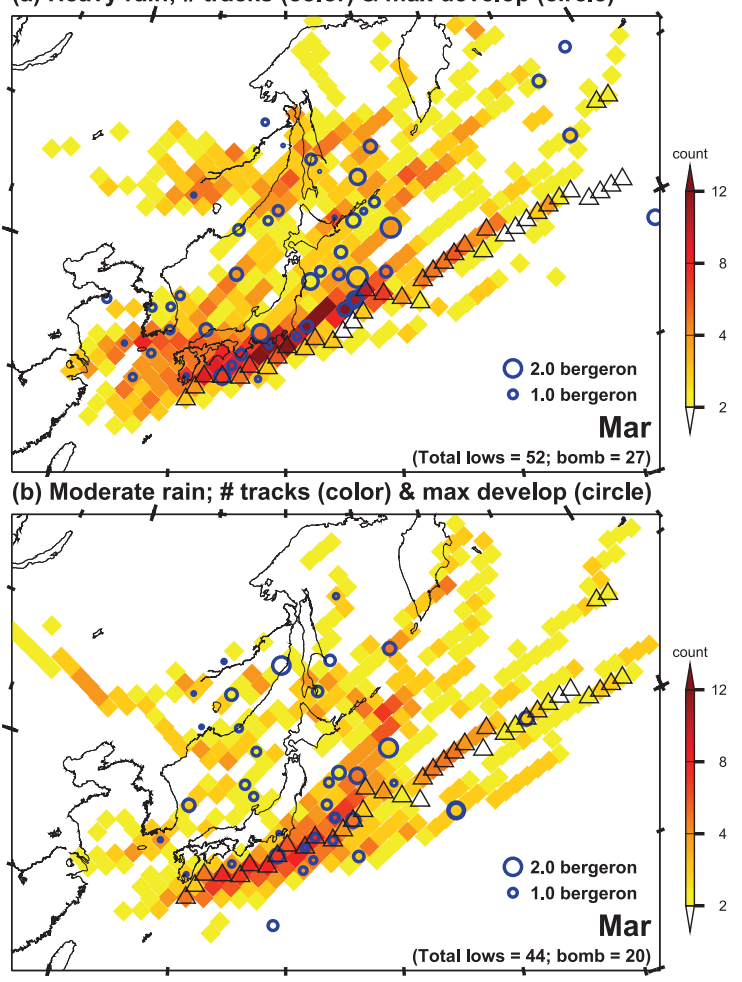

Fig. 3. Number of cyclone tracks (shade) and maximum developing points (blue circles) for (a) heavy and (b) moderate rain episodes in March. Triangles represent primary path of cyclones (same as in Fig. 1).

\section{(43 days) selected from 70 to 75 percentile of [P].}

Horizontal rainfall distributions of heavy and moderate rain episodes in March are shown in Fig. 2. Composites of $[\mathrm{P}]$ in heavy and moderate rain episodes are, respectively, approximately five- and two-times greater than the monthly climatology $\left(3.86 \mathrm{~mm} \mathrm{day}^{-1}\right)$. In both composite maps, heavy rainfall is observed in central and western Japan, particularly along the south coast. The spatial pattern shown in Fig. 2 indicates that wintertype precipitation (snowfall along the coast of the Japan Sea) is not dominant in the selected heavy and moderate rain episodes.

Table 1 shows statistics for cyclones passing over the study area (surrounded by a dashed line in Fig. 1) for the selected heavy and moderate rain episodes and for the total 28-year analysis period. The minimum SLP of cyclones is obtained from the smallest SLP within the study area. The maximum developing rate is 

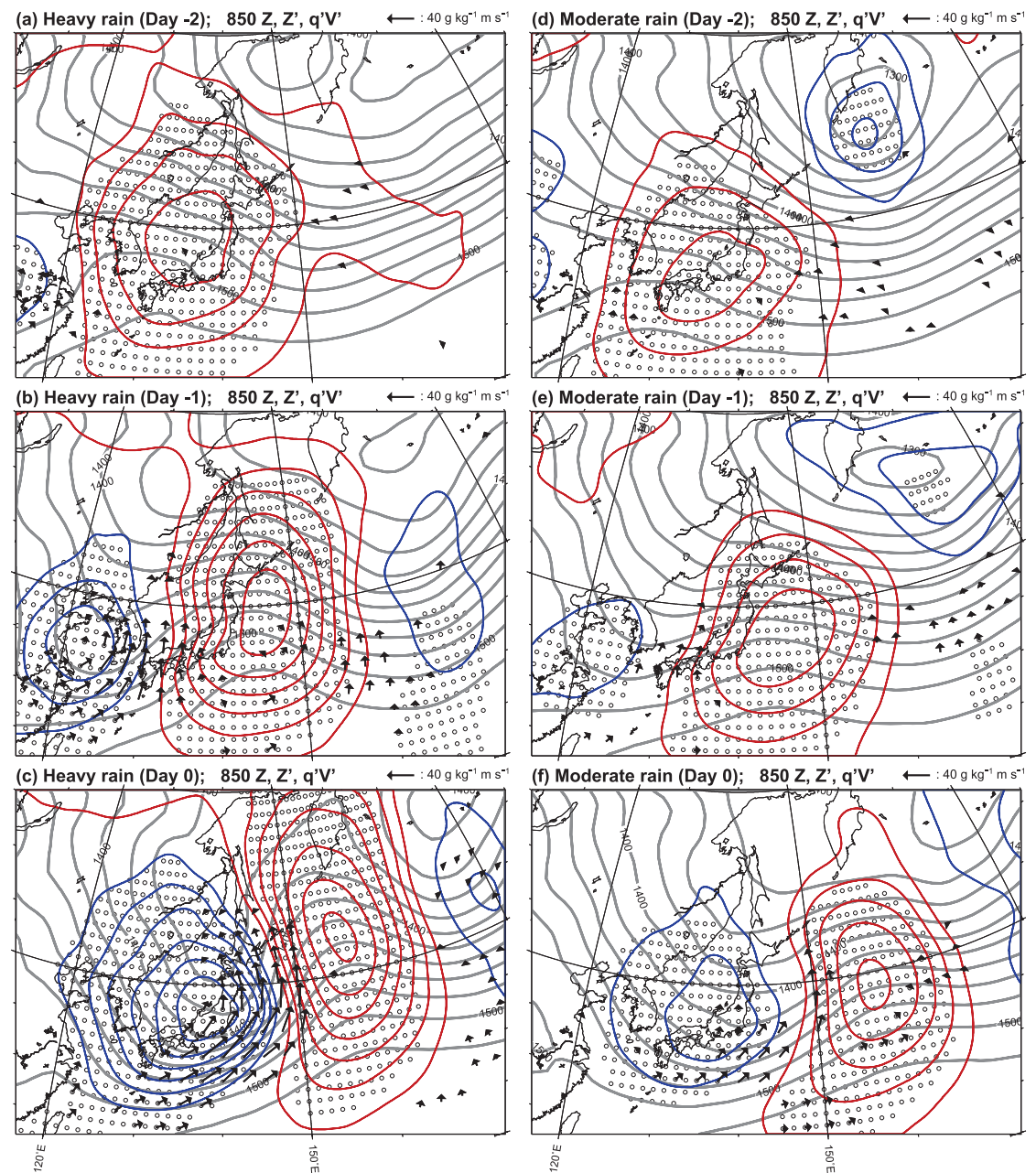

Fig. 4. Daily composites of geopotential height ( $Z$; thick gray with $20 \mathrm{~m}$ interval), total eddy component of $Z$ ( $Z^{\prime}$; $<30$ day cycle; red and blue lines with $10 \mathrm{~m}$ interval), and eddy moisture flux $\left(q^{\prime} V^{\prime} ; \geq 5 \mathrm{~g} \mathrm{~kg}^{-1} \mathrm{~ms}^{-1}\right)$ at the $850-\mathrm{hPa}$ level for heavy (left panels) and moderate (right panels) rain episodes on Days $-2,-1$, and 0 . Open circles show grids with statistical significance $\left(0.05\right.$ two tail) of $Z^{\prime}$ differences between sample averages and climatology.

selected from the largest 12-hour SLP changes with a geostrophic correction (at $60^{\circ} \mathrm{N}$; see Sanders and Gyakum 1980). Frequencies of total and explosive cyclones for heavy rain episodes are larger than those for moderate ones. The arithmetic mean of minimum SLP and maximum developing rate shows that strong and rapidly developing cyclones are more frequent for heavy rain episodes than for moderate episodes.

Individual cyclone tracks indicate differences between heavy and moderate rain episodes. Figure 3 reveals the number of tracks of all selected cyclones for heavy and moderate rain episodes. Comparing Figs. $3 \mathrm{a}$ and $3 \mathrm{~b}$, two characteristics of the cyclone tracks can be seen in these episodes. The first one is the horizontal displacement of the path of cyclones. For heavy rain episodes, cyclone tracks in both the Asian continental and Pacific coastal tracks shift slightly northward compared with those of the moderate rain episodes. The Pacific coastal cyclone track starts from the East China Sea and crosses over western Japan, whereas that in moderate rain episodes is displaced southeastward to the primary climatological path. The cyclone center rarely crosses over Japan in the moderate rain episodes. The second characteristic is the traveling direction of the cyclones. The cyclones tend to move more poleward than the climatological path, which is located along oceanic frontal zone. Spatial distribution of the maximum developments of cyclones also shows differences between heavy and moderate rain episodes (blue circles in Fig. 3). In the heavy rain episodes, the number of maximum developing cyclones increases over western Japan.

To clarify large-scale atmospheric circulations in association with heavy rain episodes, we examine transient eddy components of geopotential height, horizontal wind, and moisture fields. Figure 4 shows the composite fields of mean geopotential height $(Z)$ and moisture flux by a transient eddy component $\left(q^{\prime} V^{\prime}\right)$ at the $850-\mathrm{hPa}$ level on Days $-2,-1$, and 0 for heavy and moderate rain episodes with open circles showing grids with statistical significance of eddy component of height $\left(Z^{\prime}\right)$ differences between the composite values and climatological averages. The transient eddy component is obtained from 30-day high-pass-filtered fields using a 241-term Lanczos filter (see Duchon 1979). In the heavy rain episodes, a predominant low-level ridge $\left(Z^{\prime}>0\right)$ broadly covers the Korean Peninsula and Japan (Fig. 4a) for the two days before the heavy rain date (Day -2). A weak trough originates from southeastern China and migrates eastward after that. The ridge is intensified with eastward migration and elongated meridionally on Day -1 (Fig. 4b). On Day 0, the trough, centered at around central Japan, rapidly expands (Fig. 4c). The intensity of the ridge to the east of the trough persists and further extends meridionally along $160^{\circ} \mathrm{E}$. As an enhancement of the east-west gradient between the trough and ridge systems, southerly winds predominate between them. The strong southerly winds facilitate poleward heat (not shown) and moisture transport in the east and northeast sectors of the cyclone (Figs. 4b and 4c). On the other hand, the trough and ridge systems in moderate rain episodes are weaker than those 
of the heavy rain episodes for the period before and after rain episode (Figs. 4d-f). Thus poleward moisture flux is rather weak in the south and east of trough (Figs. $4 \mathrm{e}$ and $4 \mathrm{f}$ ).

\section{Discussion and summary}

The characteristics of cyclone activities in heavy rain episodes are summarized as follows: (1) the primary path of Pacific coastal cyclones shifts slightly westward and northward of the climatological path, (2) the maximum development of cyclones is frequently observed over western Japan, and (3) cyclones move more northward or northeastward than the primary climatological path off the east coast of Japan.

From the composite analysis of lower tropospheric circulation fields (Fig. 4), a significant increase in the poleward moisture flux over southeastern China and the East China Sea is observed for the period before a heavy rain date. Enhanced poleward moisture flux acts to develop an incipient disturbance in the west of Japan. The increase of moisture flux for the early stages of cyclones is consistent with a westward shift in the cyclone formation and maximum developing area. On the heavy rain date, significant increase of poleward moisture flux is observed from the south of Japan through mainland Japan to the Okhotsk Sea. It appears that the northward expansion of large moisture flux area contributes to a northward shift of cyclone tracks.

One of the intriguing results in this study is a low-level ridge amplification to the east of a cyclone before a rapid deepening of the trough (Figs. 4a and 4b). Bullock and Gyakum (1993) examined composite analysis of rapidly developing marine cyclones over the east of Japan $\left(35^{\circ} \mathrm{N}-40^{\circ} \mathrm{N}, 145^{\circ} \mathrm{E}-150^{\circ} \mathrm{E}\right)$ during the nine cold seasons (October-March) from 1975/76 to 1983/84. They found that the anticyclogenesis become more prominent as the increase of the developing rate of cyclones. Synoptic-scale circulation fields and their temporal changes in this study are similar to those in the previous study.

Characteristics of cyclone activities during heavy rain episodes are shown in this study, however, the primary cause of the ridge amplification is uncertain. As is well known, cyclone developing is not only affected by a heat and moisture transport in the lower troposphere but also influenced by a momentum transport in the upper troposphere. To evaluate the contribution of dynamical and thermodynamical forcing to cyclogenesis processes, quantitative research using observational data analyses and numerical experiments are required. Finally, this study highlights atmospheric circulation fields, but spatial and temporal variations of the oceanic frontal zone are not considered. As noted in Nakamura et al. (2004), the storm track axis of the western North Pacific in spring is anchored on the oceanic frontal zone, in contrast to that in winter. Information regarding the responses of cyclone activities to variations of surface baroclinicity over the ocean will enhance our understanding of the mid-latitude air-sea interaction over the western North Pacific.

\section{Acknowledgments}

We would like to thank Drs. A. Kuwano-Yoshida, S. Ogino and an anonymous reviewer for their helpful comments and suggestions. This research was supported by MEXT KAKENHI (22106005)

\section{Supplements}

Supplement 1 shows monthly mean climatology (averaged for 1982-2009) of cyclone track frequencies, horizontal SST gradient $(|\mathrm{VSST}|)$, and the maximum Eady growth rate for a cold half year (Nov-Apr).

Supplement 2 shows monthly mean frequency of cyclones passing over the study area.

\section{References}

Asai, T., Y. Kodama, and J.-C. Zhu, 1988: Long-term variations of cyclone activities in East Asia. Adv. Atmos. Sci., 5, 149-158.

Bullock, T. A., and J. R. Gyakum, 1993: A diagnostic study of cyclogenesis in the western North Pacific Ocean. Mon. Wea. Rev., 121, 65-75.

Chen, S.-J., Y.-H. Kuo, P.-Z. Zhang, and Q.-F. Bai, 1991: Synoptic climatology of cyclogenesis over East Asia, 1958-1987. Mon. Wea. Rev., 119, 1407-1418.

Chen, S.-J., Y.-H. Kuo, P.-Z. Zhang, and Q.-F. Bai, 1992: Climatology of explosive cyclones off the East Asian coast. Mon. Wea. Rev., 120, 3029-3035.

Duchon, C. E., 1979: Lanczos filtering in one and two dimensions. J. Appl. Meteor., 18, 1016-1022.

Hoskins, B. J., and P. J. Valdes, 1990: On the existence of stormtracks. J. Atmos. Sci., 47, 1854-1864.

Kamiguchi, K., O. Arakawa, A. Kitoh, A. Yatagai, A. Hamada, and N. Yasutomi, 2010: Development of APHRO_JP, the first Japanese high-resolution daily precipitation product for more than 100 years. Hydrol. Res. Lett., 4, 60-64.

Nakamura, H., T. Sampe, Y. Tanimoto, and A. Shimpo, 2004: Observed associations among storm tracks, jet streams and midlatitude oceanic fronts. in Earth's Climate: The OceanAtmosphere Interaction, Geophysical Monograph, Vol. 147, Ameri. Geophys. Union, 329-346.

Ninomiya, K., 1984: Characteristics of Baiu front as a predominant subtropical front in the summer Northern Hemisphere. $J$. Meteor. Soc. Japan, 62, 880-894.

Nishii, K., T. Miyasaka, Y. Kosaka, and H. Nakamura, 2009: Reproducibility and future projection of the midwinter stormtrack activity over the Far East in the CMIP3 climate models in relation to "Haru-Ichiban" over Japan. J. Meteor. Soc. Japan, 87, 581-588.

Onogi, K., J. Tsutsui, H. Koide, M. Sakamoto, S. Kobayashi, H. Hatsushika, T. Matsumoto, N. Yamazaki, H. Kamahori, K. Takahashi, S. Kadokura, K. Wada, K. Kato, R. Oyama, T. Ose, N. Mannoji, and R. Taira, 2007: The JRA-25 reanalysis. J. Meteor. Soc. Japan, 85, 369-432.

Reynolds, R. W., T. M. Smith, C. Liu, D. B. Chelton, K. S. Casey, and M. G. Schlax, 2007: Daily high-resolution-blended analyses for sea surface temperature. J. Climate, 20, 54735496.

Sanders, F., and J. R. Gyakum, 1980: Synoptic-dynamic climatology of the "bomb". Mon. Wea. Rev., 108, 1589-1606.

Serreze, M. C., J. E. Box, R. G. Barry, and J. E. Walsh, 1993: Characteristics of Arctic synoptic activity, 1952-1989. Meteorol. Atmos. Phys., 51, 147-164.

Takahashi, H., 1993: Synoptic condition over East Asia during the early-summer rainy season (Baiu season) from the point of view of the temporal continuity of rainfall in the southwestern part of Japan. J. Meteor. Soc. Japan, 71, 611-632.

Uemura, H., 1981: On the precipitation and cloud areas associated with a depression. Tenki, 28, 225-236 (in Japanese).

Whittaker, L. M., and L. H. Horn, 1984: Northern Hemisphere extratropical cyclone activity for four mid-season months. $J$. Climatology, 4, 297-310.

Yatagai, A., O. Arakawa, K. Kamuguchi, H. Kawamoto, M. I. Nodzu, and A. Hamada, 2009: A 44-year daily gridded precipitation dataset for Asia based on a dense network of rain gauges. SOLA, 5, 137-140.

Yoshida, A., and Y. Asuma, 2004: Structures and environment of explosively developing extratropical cyclones in the Northwestern Pacific region. Mon. Wea. Rev., 132, 1121-1142.

Yoshiike, S., and R. Kawamura, 2009: Influence of wintertime large-scale circulation on the explosively developing cyclones over the western North Pacific and their downstream effects. J. Geophys. Res., 114, D13110, doi: 10.1029/2009JD 011820 .

Manuscript received 2 February 2012, accepted 20 April 2012 SOLA: http://www.jstage.jst.go.jp/browse/sola 